\title{
Diagnosis and Management of Acute Pulmonary Embolism
}

\author{
Chandra Prakash Dokwal ${ }^{1}$
}

Pulmonary embolism (PE) is a common and potentially lethal condition. The incidence of $\mathrm{PE}$ in the USA is 2 to 3 cases per 1000 persons per year, and accounts for 200,000 to 300,000 hospitalizations in a year., ${ }^{1,2}$ The short-term mortality of acute PE varies from $<2 \%$ in those with nonmassive PE to $>65 \%$ in those who develop hemodynamic shock. ${ }^{3,4} \mathrm{PE}$ is also the direct cause of $5 \%$ to $10 \%$ of all in-hospital deaths.,

$\mathrm{PE}$ is the complication of deep vein thrombosis (DVT) in most cases, and about $50 \%$ of patients with proximal DVT have usually asymptomatic PE at lung scan. ${ }^{7}$ DVT has also been documented in lower limbs in about $70 \%$ of patients with PE. ${ }^{8} \quad$ Early diagnosis and appropriate treatment considerably reduces the morbidity and mortality in acute PE.

\section{Definitions}

PE is traditionally divided into 3 categories: massive, submassive, and low-risk PE. The massive PE was originally defined on the basis of angiographic burden of emboli ${ }^{9}$ but it has not been proven of much clinical relevance. In patients with acute $\mathrm{PE}$, the age and clinical co morbidities significantly influence the prognosis. $^{10,11,12}$ A patient with submassive PE may have a high-risk for complications in the presence of comorbidities. ${ }^{13}$ Similarly, patients with low-risk PE who are elderly or have other clinical illnesses may still have increased PE-related complications. ${ }^{13,15}$

The American Heart Association (AHA) has recently proposed to define these different categories of PE as follows. ${ }^{15}$

(a) Massive PE: Acute PE in patients with sustained hypotension (BP $<90 \mathrm{~mm}$ Hg for $>15$ min or requiring inotropic support), or persistent profound bradycardia (heart rate < 40/min with shock).

(b) Submassive PE: Acute PE in patients without systemic hypotension but with either right ventriclular (RV) dysfunction or evidence of myocardial necrosis. The RV dysfunction is defined by the presence of at least 1 of the followings: 1) RV dilation (RV diameter/LV diameter $>0.9$ ) or RV systolic dysfunction on echocardiography; 2) RV dilation on CT; 3) Elevation of BNP (>90 pg/mL); 4) Elevation of N-terminal pro-BNP (>500 pg/mL); or 5) New RBBB, anteroseptal ST elevation or depression, or anteroseptal T-wave inversion on ECG.

Myocardial necrosis is present if Troponin I is $>0.4 \mathrm{ng} / \mathrm{mL}$ or troponin $\mathrm{T}$ is $>0.1 \mathrm{ng} / \mathrm{mL}$.

(c) Low risk PE: Acute PE in patients who are normotensive with normal biomarker levels and no RV dysfunction on imaging studies.

\section{Diagnosis of PE}

A major problem in the diagnosis of PE is that symptoms and signs are often non-specific, and most patients suspected of PE do not have it. In the diagnostic strategies in patients with suspected PE, the initial focus is on identifying those in whom PE can be ruled out. ${ }^{16,17}$

A patient with suspected PE should first have assessment of the probability of $\mathrm{PE}$, so as to identify those with a high or intermediate clinical probability for PE needing prompt anticoagulant treatment while awaiting their diagnostic results including imaging studies. ${ }^{18}$ The estimate of pretest probability (PTP) for PE has a significant impact on choice and interpretation of diagnostic 
tests as well. For example, a patient with high probability for PE should directly be subjected to imaging studies without D-dimer test. Also patients with a low PTP for PE and a negative D-dimer result need no further studies. ${ }^{16,17,19}$

The pretest probability for PE can be assessed empirically using either empirical clinical assessment or with prediction rules or scores.

\section{Clinical Prediction Rules}

Before proceeding with the testing for suspected pulmonary embolism, the pretest probability of $\mathrm{PE}$ is estimated. It is recommended that validated clinical prediction rules (CPRs) be used to estimate pretest probability of PE and to interpret test results. These rules have improved the diagnostic work-up of patients with suspected PE. PE can be safely excluded in most patients with normal D-dimer result, if a clinical prediction rule suggests "PE unlikely", without the need for further testing with computed tomographic pulmonary angiography (CTPA) or ventilation-perfusion (V/Q) scintigrapy.

Several statistically derived scores or clinical prediction rules (CPRs) have been developed in the past that provide estimates of the probability of PE using clinical information. A prediction rule for acute $\mathrm{PE}$ was first described by Hoellerich and colleagues in $1986{ }^{20}$ however it was not validated in large clinical studies. Subsequently, several CPRs have been described, of these, the Wells score ${ }^{21}$ and the Geneva score ${ }^{22}$ are the most widely validated. Many of these CPRs have also been modified so as to make them simpler and easier to use in clinical practice, such as modified Wells score ${ }^{23}$, revised Geneva score ${ }^{24}$, and simplified revised Geneva score. $^{25}$

The most widely used CPRs are Wells score and the revised Geneva score for suspected PE. Although all scores have been validated in outpatients, only the Wells score has been validated in hospitalized patients. ${ }^{26}$ Several meta-analyses performed in patients with acute PE have documented that different CPRs have similar accuracy in assessing clinical probability of PE, but are not totally equivalent. ${ }^{17,26}$ In high prevalence situation for $\mathrm{PE}$, a rule with higher specificity is desirable, whereas in a lower prevalence situation, a rule with higher sensitivity is advisable. ${ }^{17}$

\section{D-dimer Testing}

D-dimer is a degradation product of cross-linked fibrin. It is highly sensitive for the diagnosis of acute thrombotic process including $\mathrm{PE}$, but lacks specificity.

PE can be safely excluded in those who have a low or intermediate pretest probability (PTP) which is derived from one of the clinical prediction rules as discussed earlier, and a negative D-dimer result. ${ }^{16,17,19}$ These patients do not require anticoagulant treatment as two meta-analyses have also confirmed these results. ${ }^{27,28}$ The recurrence rate of subsequent venous thromboembolism (VTE) in those not treated on the basis of low pretest probability (PTP) and a negative D-dimer testing is $<1 \%$.

The main limitation of D-dimer is its low specificity. Apart from acute PE and deep vein thrombosis (DVT), it is also elevated in other conditions, including surgery, malignancy, infection, pregnancy and acute myocardial infarction. ${ }^{29}$

\section{Compression ultrasonography (CUS)}

A high percentage of proximal DVT progresses to PE. The contrast venography has traditionally been considered the gold standard for the diagnosis of DVT, however in recent years CUS has largely replaced it in the diagnosis of DVT of lower extremities. CUS reliably confirms or rules out proximal DVT. It may also be performed as initial imaging modality for evalu 
ation of suspected PE in critically ill unstable patients and pregnant women.

In patients with indeterminate ventilation/perfusion (V/Q) scan, CUS plays an important role. ${ }^{29}$ The presence of proximal DVT in a symptomatic patient with contraindications for CT pulmonary angiography (CTPA) is considered sufficient to rule in PE. However, a negative CUS does not rule out $\mathrm{PE}$, as $>50 \%$ of patients with confirmed $\mathrm{PE}$ have a negative CUS. ${ }^{30}$

\section{Ventilation/perfusion (V/Q) scanning}

For many decades, radionuclide V/Q scanning was the modality of choice for the diagnosis of PE. In recent years, it has been largely supplanted by CT pulmonary angiography (CTPA). Both CTPA and V/Q scanning can safely rule out $\mathrm{PE}$ if the results are negative. ${ }^{29}$ V/Q scan may be preferable in premenopausal women (only perfusion scintigraphy in pregnancy advocated), and patients with renal insufficiency or dye allergy. ${ }^{31}$ V/Q scan is conventionally reported as normal, high probability, or non-high probability scan. A normal V/Q scan essentially excludes PE. A high-probability scan is one in which there is at least one segmental defect on perfusion scintigraphy with normal ventilation scintigraphy. However a large number of V/Q scans are reported as non-high or indeterminate probability scan. In a prospective study directly comparing CTPA with V/Q scan in patients with suspected PE, $54 \%$ of V/Q scans were reported as non-diagnostic. ${ }^{29} \mathrm{~A}$ nondiagnostic V/Q scan combined with a negative venous ultrasound excludes PE if clinical suspicion is not high ${ }^{32}$, however, CTPA should be considered in those with high clinical likelihood for PE.

In recent years, the single-photon-emission CT (SPECT) scan appears to be a promising modality in the diagnosis of PE. Some studies have even suggested that SPECT may have a higher sensitivity compared to CTPA for diagnosis of acute PE than CTPA ${ }^{33,34}$, although such observations need further evaluation.

\section{Multidetector Computed Tomographic Pulmonary Angiography (CTPA)}

CTPA has replaced conventional pulmonary angiography as the reference test for PE. CTPA is highly sensitive (96\% to $100 \%$ ) with a specificity of about $98 \%$ for the diagnosis of PE. A normal CTPA safely rules out PE if clinical pretest probability is low or intermediate. ${ }^{35,36,37}$ In a study, only $1.3 \%$ of patients with high pretest probability of PE but a negative CTPA subsequently developed PE during a 3-month follow up period. ${ }^{38}$ In normotensive patients, the CTPA may also allow risk stratification before echocardiography results. A further advantage of CTPA is that it may provide alternative diagnoses or detect unsuspected lung pathology.

\section{Medical Resonance Angiography (MRA)}

The role of magnetic resonance pulmonary angiography (MRA) in acute $\mathrm{PE}$ is under investigations, however, it has a much less sensitivity and specificity compared to CTPA. In the recent PIOPED III study, the sensitivity of MRA was only $78 \%$ with an overall specificity of 99\%. ${ }^{40}$ Presently, MRA and thigh vein MR venography is considered only in patients in whom other imaging studies can not be performed.

\section{Pulmonary angiography}

The catheter pulmonary angiography was traditionally considered the gold standard for the diagnosis of $\mathrm{PE}$, and was the standard practice since late 1960s onwards. However, CTPA and V/Q scanning have almost replaced it in the evaluation of PE. It is now rarely performed as an isolated diagnostic procedure. Multiple studies have documented the superiority of CTPA over pulmonary angiograpy in the diagnosis of PE. 


\section{Risk Assessment and stratification}

Current guidelines emphasize the importance of an early risk stratification of patients with acute pulmonary embolism (PE) to allow assessment of the individual prognosis and guide therapeutic decision-making. ${ }^{41}$ The Pulmonary Embolism Severity Index (PESI) ${ }^{13}$ and its simplified version (SPESI) ${ }^{42}$ are most widely used clinical scores to date.

Hemodynamic instability is an important indicator of poor prognosis. The evaluation of hemodynamic status, signs of RV dysfunction and myocardial injury, and the assessment of additional patient-related risk factors are required for optimal risk stratification. ${ }^{41}$ However, differentiating submassive PE from low-risk PE in patients may be difficult at times, particularly when they are hemodynamically stable.

Patients with acute PE who die have higher D-dimer levels compared to those who survive. ${ }^{25,43,44}$ Acute RV failure is the main cause of death in acute PE, and RV dysfunction on echocardiography is associated with high mortality. ${ }^{45}$ A recent meta- analysis has also confirmed this association. ${ }^{46}$

Brain natriuretic peptides (BNPs) and N-terminal proBNP (NT-proBNP) are specific markers of stress on ventricular wall. A strong correlation exists between levels of these markers and RV dysfunction assessed by echocardiography. Patients with acute PE and high levels of BNP and NT-proBNP have a higher mortality or adverse events ${ }^{25,47}$, including even those with normotenisve PE. ${ }^{46}$

Elevated values of cardiac troponins T and I are associated with increased risk of short-term mortality in patients with acute PE including those who are hemodynamically stable. ${ }^{46,48}$

\section{Treatment}

Patients with acute PE are stratified according to prognosis. Although treatment strategies are
UFH and LMWHs are equally effective without clearly defined for hypotensive, hemodynamically unstable patients with massive PE, stratifying normotensive patients into an intermediaterisk (submassive $\mathrm{PE}$ ) and a low-risk subgroup is still problematic. ${ }^{15,49}$

Acute massive PE with cardiogenic shock or severe RV dysfunction should be treated with immediate thrombolysis, percutaneous mechanical thrombectomy (PMT) or surgical embolectomy. ${ }^{15,41}$ Anticoagulaltion should be started in patients with intermediate or high clinical probability of $\mathrm{PE}$ while they are undergoing evaluation for PE. All patients with confirmed PE should receive prompt anticoagulant therapy with unfractionated heparin (UFH), a low-molecular weight heparin (LMWH), or fondaparinux. ${ }^{15,41}$

\section{Heparins}

Heparins act by binding to antithrombin which inactivates thrombin and several other activated coagulation factors including factor $\mathrm{Xa}$. Treatment with unfractionated heparin (UFH) should be initiated without delay in patients with highrisk $\mathrm{PE}$ as low molecular weight heparins (LMWHs) have not been evaluated in this setting. ${ }^{41}$

Therapy in acute PE is usually started with 80 units/kg of UFH as bolus followed by 18 units/kg/hour by continuous IV infusion with monitoring of activated partial thromboplastine time (aPTT between 1.5 to 2.5 times control). ${ }^{50}$ However, the dose of UFH should not be increased $>40,000$ units/day despite aPTT ratio being in the subtherapeutic range, if the antifactor Xa heparin level is $>0.35 \mathrm{IU} / \mathrm{mL}$ (51). UFH is also preferred over LMWHs in patients with severe renal impairment with creatinine clearance $<30 \mathrm{ml} / \mathrm{min}$ and in those at high-risk of bleeding.

In patients with submassive or low-risk PE, both 
an increase in recurrent VTE or all-cause mortality in either group. ${ }^{52,53}$ LMWHs have a more predictable dose-response effect, hence routine laboratory monitoring with anti-Xa levels is not necessary except in those with severe renal failure and in females during pregnancy. ${ }^{54}$ Compared to UFH, LMWHs have a lower risk of immune-mediated thrombocytopenia or osteoporosis. As LMWHs are primarily excreted by the kidneys, in patients with severe renal impair ment (creatinine clearance $<30 \mathrm{~mL} / \mathrm{min}$ ), either UFH is used, or the dose of LMWHs is decreased with anti-Xa level monitoring. ${ }^{55}$

Fondaparinux is a synthetic pentasaccharide. It has potent and specific antithrombin-mediated anti-Xa activity. It has an excellent bioavailability and a long half-life. It has been used in submassive and low-risk PE with equal efficacy and safety as UFH. ${ }^{4}$

\section{Table 1. Approved LMWHs and fondaparinux for treatment of acute $\mathbf{P E}^{41}$}

\begin{tabular}{|l|l|l|}
\hline & Dose & Interval \\
\hline Enoxaparin & $1 \mathrm{mg} / \mathrm{kg}$ & $\begin{array}{l}\text { Every } 12 \text { hour } \\
\text { Once daily }\end{array}$ \\
& Or $1.5 \mathrm{mg} / \mathrm{kg}$ & Once daily \\
\hline Tinzaparin & $175 \mathrm{U} / \mathrm{kg}$ & Once daily \\
\hline Fondaparinux & $5 \mathrm{mg}($ body wt $<50 \mathrm{~kg})$ & \\
& $7.5 \mathrm{mg}$ (B.W. $50-100 \mathrm{~kg})$ & \\
& $10 \mathrm{mg}$ (B.W. $>100 \mathrm{~kg})$ & \\
\hline
\end{tabular}

\section{Thrombolysis}

Thrombolysis should be promptly started in those with high-risk PE presenting with cardiogenic shock and/or persistent hypotension, severe RV dysfunction, or major myocardial necrosis. ${ }^{15,41}$ With fibrinolytic agents the lung perfusion is rapidly restored with $\sim 1 / 3^{\text {rd }}$ reduction in total perfusion defect at 24 hours.
However, by 1 week, both heparin and adjunctive thrombolytic therapy achieve similar reduction in perfusion effect of about $2 / 3^{\text {rd }}$. No definitive therapeutic advantage of catheter-directed thrombolysis has been documented when compared with intravenous thrombolysis. The approved thrombolytic drugs are enumerated in table 1.

Table 2. Dosage of plasminogen activating fibrinolytics for acute PE

\begin{tabular}{|l|l|}
\hline & Fibrinolytic dose \\
\hline Streptokinase & $\begin{array}{l}250,000-\mathrm{IU} \text { IV bolus over } 30 \mathrm{~min} \text {, followed } \\
\text { by } 100,000-\mathrm{IU} / \mathrm{h} \text { infusion for } 12-24 \mathrm{~h}\end{array}$ \\
\hline Urokinase & $\begin{array}{l}4400-\mathrm{IU} / \mathrm{kg} \text { bolus over } 10 \mathrm{~min}, \text { followed by } \\
4400-\mathrm{IU} / \mathrm{kg} / \mathrm{h} \text { infusion for } 12-24 \mathrm{~h} \text {; or, } \\
\text { accelerated regimen: } 3 \text { million IU over } 2 \mathrm{~h}\end{array}$ \\
\hline Alteplase & $\begin{array}{l}100-\mathrm{mg} \text { IV infusion over } 2 \mathrm{~h} \text { or, } 0.6 \mathrm{mg} / \mathrm{kg} \\
\text { over } 15 \mathrm{~min} \text { (max } 50 \mathrm{mg})\end{array}$ \\
\hline Reteplase & \begin{tabular}{l} 
Double $10-\mathrm{U}$ IV bolus 30 min apart \\
\hline Tenecteplase
\end{tabular} \\
& $\begin{array}{l}\text { Weight-adjusted rapid IV bolus over } 5 \mathrm{~s}(30- \\
\mathrm{mg} \text { with a } 5 \mathrm{mg} \text { step every } 10 \mathrm{~kg} \text { from }\end{array}$ \\
\hline
\end{tabular}




\section{REVIEW ARTICLE}

\section{Table 3. Contraindications to thrombolysis ${ }^{56}$}

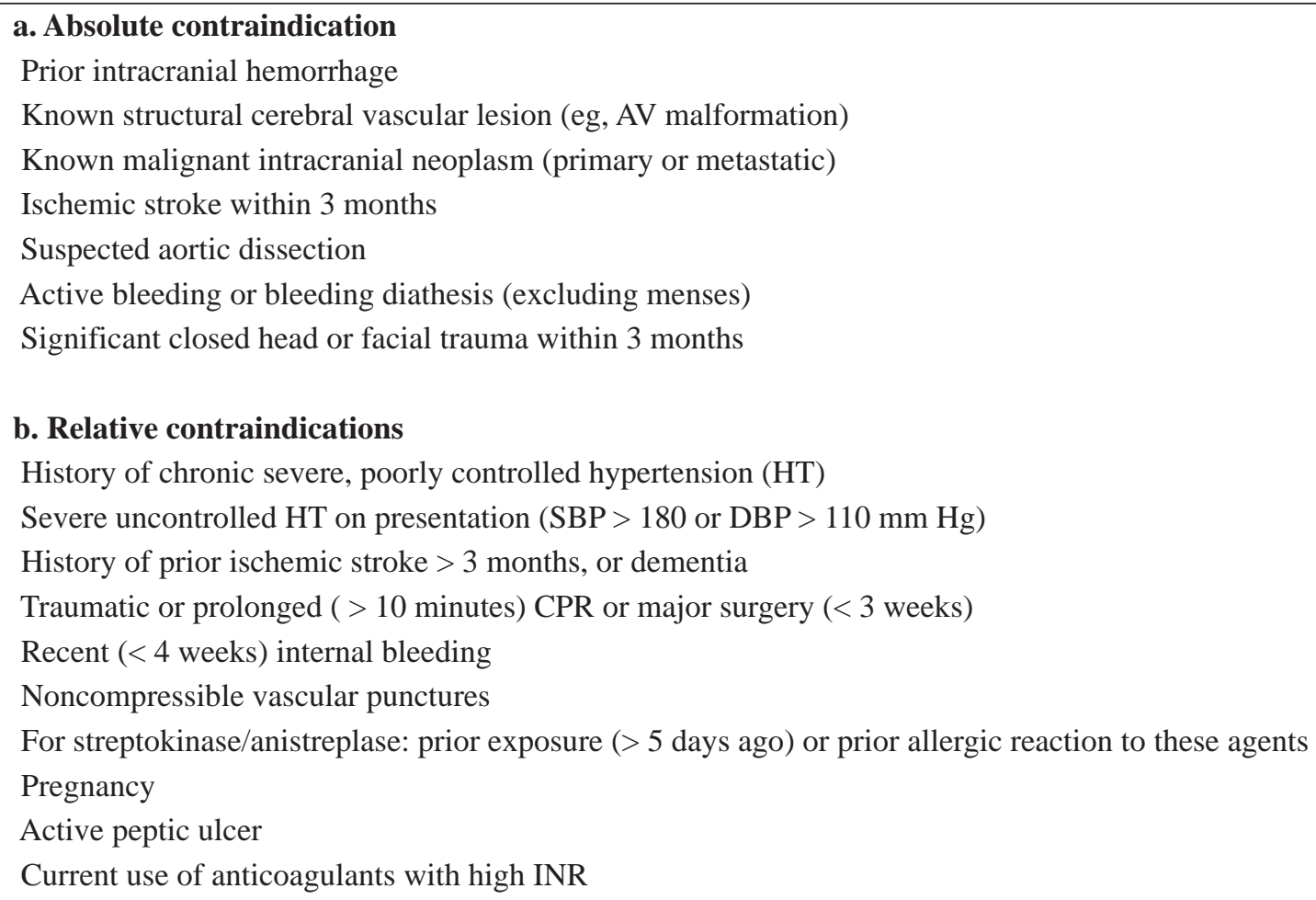

\section{b. Relative contraindications}

History of chronic severe, poorly controlled hypertension (HT)

Severe uncontrolled HT on presentation (SBP > 180 or DBP > $110 \mathrm{~mm} \mathrm{Hg}$ )

History of prior ischemic stroke $>3$ months, or dementia

Traumatic or prolonged ( $>10$ minutes) CPR or major surgery ( $<3$ weeks)

Recent $(<4$ weeks) internal bleeding

Noncompressible vascular punctures

For streptokinase/anistreplase: prior exposure (> 5 days ago) or prior allergic reaction to these agents

Pregnancy

Active peptic ulcer

Current use of anticoagulants with high INR

\section{Catheter-based Interventions and Surgical Embolectomy}

Percutaneous mechanical thrombectomy (PMT) can be considered as an alternative when thrombolysis is contraindicated or has failed. In PMT, the thrombus removal is achieved via mechanical thrombus fragmentation, maceration, and/or aspiration. ${ }^{57,58}$ In a meta-analysis, the combined approach with catheter-based clot fragmentation and local thrombolysis was superior to PMT only. ${ }^{59}$ Surgical embolectomy is an option in those with massive or submassive PE with RV dysfunction when thrombolysis is contraindicated or has failed. ${ }^{58,60}$

\section{Oral anticoagulants}

For many decades, Vitamin $\mathrm{K}$ antagonists (VKAs) were the only oral anticoagulant drugs available. Recently, other new oral drugs, namely the direct thrombin inhibitor dabigatran etexilate and direct factor-Xa inhibitor rivaroxaban have been approved for clinical use. These new compounds have the potential to replace VKAs and heparins in many patients. These drugs are used in fixed dose therapy without routine coagulation monitoring, and have few drug-drug or drug-food interactions. Presently, VKAs are the drug of choice for the prolonged anticoagulation, and have been documented to be effective and safe. VKAs include warfarin, acenocoumarol, phenprocoumon, and fluindione, however, warfarin is the most commonly used anticoagulant drug. VKAs can be started either simultaneously with or few days after starting heparin therapy. The meta-analyses of studies comparing VKAs with prolonged LMWH have documented equal efficacy in preventing VTE recurrences. ${ }^{61,62}$ Vitamin K antagonist (VKA) therapy is used for at least 3 months in patients after initial therapy with injectable anticoagulant. In patients with high-risk for recurrent PE or DVT, an extended therapy is needed.

\section{Conclusions}

Acute PE is potentially a lethal problem. A 
prompt diagnosis and immediate anticoagula tion therapy improve patient outcome. Patients with massive PE should receive prompt thrombolysis, catheter-based surgical intervention, or surgical embolectomy. In non-massive and low-risk PE, a pretest clinical probability with one of the clinical prediction rules is important before clinical tests are ordered. The investigations for PE should be performed in sequences to avoid false-positive and false-negative results. Oral anticoagulants with VKAs are continued for at least 3 months. Selected patients may continue to receive VKAs for much longer period. Novel oral anticoagulants are in the pipe-lines and may change the therapeutic approach in acute PE.

\section{References}

1. Anderson FA Jr, Wheeler HB, Goldberg RJ, Hosmer DW, Patwardhan NA, Jovanovic B, et al. A population-based perspective of the hospital incidence and case-fatality rates of depp vein thrombosis and pulmonary embolism. The Worcester DVT study. Arch Intern Med. 1991;151:933-38.

2. Silverstein MD, Heit JA, Mohr DN, Petterson TM, O'Fallon WM, Melton LJ 3rd. Trends in the incidence of deep vein thrombosis and pulmonary embolism: a 25-year population-based study. Arch Intern Med. 1998;158:585-93.

3. Simonneau G, Sors $\mathrm{H}$, Charbonnier B, Page Y, Laaban JP, Azarian R, et al. A comparison of low-molecular-weight heparin with unfractionated heparin for acute pulmonary embolism. The THESEE Study Group (Tinzaparine ou Heparine Standard: Evaluations dans l'Embolie Pulmonaire). N Engl J Med. 1997;337:663-669.

4. Buller HR, Davidson BL, Decousus H, Gallus A, Gent M, Piovella F, et al. Matisse Investigators. Subcutaneous fondaparinux versus intravenous unfractionated heparin inthe initial treatment of pulmonary embo lism. N Engl J Med. 2003;349:1695-1702.

5. Lindblad B, Sternby NH, Bergqvist D. Incidence of venous thromboembolism verified by necropsy over 30 years. BMJ. 1991;302:709-11.

6. Alikhan R, Peters F, Wilmott R, Cohen AT. Fatal pulmonary embolism in hospital patients; a necropsy review. J Clin Pathol. 2004;57:1254-57.

7. Moser KM, Fedullo PF, Littejohn JK, Crawford R. Frequent asymptomatic pulmonary embolism in patients with deep venous thrombosis. JAMA. 1994;271:223-25.

8. Kearon C. Natural history of venous thromboembolism. Circulation. 2003;107(23 suppl. 1):122-30.

9. Miller GA, Sutton GC, Kerr IH, Gibson RV, Honey M. Comparison of streptokinase and heparin in treatment of isolated acute massive pulmonary embolism. Br Med J. 1971;2:681-684.

10. Goldhaber SZ, Visani L, De Rosa M. Acute pulmonary embolism: clinical outcomes in the International Cooperative Pulmonary Embolism Registry (ICOPER). Lancet. 1999;353:1386-1389.

11. Grifoni S, Olivotto I, Cecchini P, Pieralli F, Camaiti A, Santoro G, et al. Short-term clinical outcome of patients with acute pulmonary embolism, normal blood pressure, and echocardiographic right ventricular dysfunction. Circulation. 2000;101:2817-2822.

12. Laporte S, Mismetti P, Décousus H, Uresandi F, Otero R, Lobo JL, et al. RIETE Investigators. Clinical predictors for fatal pulmonary embolism in 15,520 patients with venous thromboembolism: findings from the Registro Informatizado de la Enfermedad Trombo-Embolica venosa (RIETE) Registry. Circulation. 2008;117:1711-1716.

13. Aujesky D, Obrosky DS, Stone RA, Auble TE, Perrier A, Cornuz J, et al. Derivation and validation of a prognostic model for pulmonary embolism. Am J Respir Crit Care Med. 2005;172:1041-1046.

14. Wicki J, Perrier A, Perneger TV, Bounameaux H, Junod AF. Predicting adverse outcome in patients with acute pulmonary embolism: a risk score. Thromb Haemost. 2000;84:548 -552.

15. Jaff MR, McMurtry MS, Archer SL, Cushman M, Goldenberg N, Goldhaber SZ, et al. Management of massive and submassive pulmonary embolism, iliofemoral deep vein thrombosis, and chronic thromboembolic pulmonary hypertension: a scientific statement from the American Heart Association. Circulation. 2011;123:1788-1830.

16. Kruip MJ, Leclercq MG, van der Heul C, Prins MH, Büller HR. Diagnostic strategies for excluding pulmonary embolism in clinical outcome studies. A systematic review. Ann Intern Med. 2003;138:941-51.

17. Lucassen W, Geersing G-J, Erkens PM, Reitsma JB, Moons KG, Büller $\mathrm{H}$ et al. Clinical decision rules for excluding pulmonary embolism: a meta-analysis. Ann Intern Med. 2011;155:448-60

18. Goldhaber SZ, Bounameaux H. Pulmonary embolism and deep vein thrombosis. Lancet. 2012;379:1835-46.

19. Pasha SM, Klok FA, Snoep JD, Mos IC, Goekoop RJ, Rodger MA, et al. 
Safety of excluding acute pulmonary embolism based on an unlikely clinical probability by the Wells rule and normal D-dimer concentration: a meta-analysis. Thromb Res. 2010;125:e123-7.

20. Hoellerich VL, Wigton RS. Diagnosing pulmonary embolism using clinical findings. Arch Intern Med. 1986;146:1699-704.2009;64(10):869-875.

21. Wells PS, Anderson DR, Rodger M, Ginsberg JS, Kearon C, Gent M, et al. Derivation of a simple clinical model to categorize patients probability of pulmonary embo lism: increasing the models utility with the SimpliRED D-dimer. Thromb Haemost. 2000;83:416-20.

22. Wicki J, Perneger TV, Junod AF, Bounameaux H, Perrier A. Assessing clinical probability of pulmonary embolism in the emergency ward: a simple score. Arch Intern Med. 2001;161:92-7.

23. Gibson NS, Sohne M, Kruip MJ, Tick LW, Gerdes VE, Bossuyt PM, et al. Christopher study investigator. Further validation and simplification of the Wells clinical decision rule in pulmonary embolism. Thromb Haemostat. 2008;99:229-34.

24. Le Gal G, Righini M, Roy PM, Sanchez O, Aujesky D, Bounameaux $\mathrm{H}$, et al. Prediction of pulmonary embolism in the emergency department: the revised Geneva score. Ann Intern Med. 2006;144:165-71

25. Klok FA, Mos IC, Nijkeuter M, Righini M, Perrier A, Le Gal G et al. Simplification of the revised Geneva score for assessing clinical probability of pulmonary embolism. Arch Intern Med. 2008;168:2131-36.

26. Ceriani E, Combescure C, Le Gal G, Nendaz M, Perneger T, Bounameaux $\mathrm{H}$, et al. Clinical prediction rules for pulmonary embolism: a systematic review and meta-analysis. J Thromb Haemost. 2010;8:957-70.

27. Stein PD, Hull RD, Patel KC, Olson RE, Ghali WA, Brant R, et al. D-dimer for the exclusion of acute venous thrombosis and pulmonary embolism: a systematic review. Ann Intern Med. 2004; 140(8):589-602.

28. Di Nisio M , Squizzato A , Rutjes AW, Büller HR, Zwinderman AH, Bossuyt PM. et al. Diagnostic accuracy of D-dimer test for exclusion of venous thromboembolism: a systematic review. J Thromb Haemost 2007;5(2):296-304 .

29. Kelly J, Rudd A, Lewis , Hunt B. Plasma D-dimer in the diagnosis of venous thromboembolism. Arch Intern Med 2002;162:747-56. 29a. Anderson DR , Kahn SR , Rodger MA , Kovacs MJ, Morris T, Hirsch A, et al. Computed tomographic pulmonary angiography vs ventilation-perfusion lung scanning in patients with suspected pulmonary embolism: a randomized controlled trial. JAMA. 2007;298 (23):2743-53.
30. Turkstra F , Kuijer PM , van Beek EJ , Brandjes DP , ten Cate JW , Büller HR . Diagnostic utility of ultrasonography in patients with acute pulmonary embolism and reduction in mortality in patients with right ventricular dysfunction by pulmonary of leg veins in patients suspected of having pulmonary embolism. Ann Intern Med. 1997;126(10):775-781.

31. Moores LK, King CS, Holley AB. Current approach to the diagnosis of acute nonmassive pulmonary embolism. Chest. 2011;140:5090-18.

32. Wells PS, Anderson DR, Rodger M, Stiell I, Dreyer JF, Barnes D, et al. Excluding pulmonary embolism at the bedside without diagnostic imaging: management of patients with suspected pulmonary embolism presenting to the emergency department by using a simple clinical model and D-dimer. Ann Intern Med. 2001;135(2):98-107.

33. Reinartz P, Wildberger JE, Schaefer W, Nowak B, Mahnken AH, Buell U. Tomographic imaging in the diagnosis of pulmonary embolism: a comparison between V/Q lung scintigraphy in SPECT technique and multislice spiral CT. J Nucl Med 2004;45:1501-8.

34. Gutte H, Mortensen J, Jensen CV, Johnbeck CB, von der Recke P, Petersen CL, et al. detection of pulmonary embolism with combined ventilation-perfusion SPECT and low-dose CT: head-to-head comparison with multidetector CT angiography. J Nucl Med. 2009;50:1987-92.

35. Kruip MJ, Slob MJ, Schijen JH, Van Der Heul C, Buller HR. Use of a clinical deci sion rule in combination with D-dimer concentration in diagnostic workup of patients with suspected pulmonary embolism: a prospective management study. Arch Intern Med. 2002;162:1631-35.

36. Musset D, Parent F, Meyer G, Maitre S, Girard P, Leroyer C, et.al. Diagnostic strategy for patients with suspected pulmonary embolism: a prospective multicentre outcome study. Lancet. 2002;360:1914-20.

37. Agnelli G , Becattini C. Acute pulmonary embolism. N Engl J Med. 2010;363(3 ):266 - 274.

38. Pollack CV, Schreiber D, Goldhaber SZ, Slattery D, Fanikos J, O'Neil BJ, et al. Clinical characteristics, management, and outcomes of patients diagnosed with acute pulmonary embolism in the emergency department: initial report of EMPEROR (Multicenter Emergency Medicine Pulmonary Embolism in the Real World Registry). J Am Coll Cardiol. 2011;57:700-06. 
Diagnosis and Management of Acute Pulmonary Embolism

39. Patel S, Kazerooni EA, Cascade PN. Pulmonary embolism: optimization of small artery visualization at multi-detector row CT. Radiology. 2003;227:455-60

40. Stein PD, Chenevert TL, Fowler SE, Goodman LR, Gottschalk A, Hales CA, et al. Gadolinium-enhanced magnetic resonance angiography for pulmonary embolism. A multicenter prospective study (PIOPED III). Ann Intern Med. 2010;152:434-43.

41. Torbicki A, Perrier A, Konstantinides S, Agnelli G, Galiè N, Pruszczyk P, et al. Guidelines on the diagnosis and management of acute pulmonary embolism: the Task Force for the Diagnosis and Management of Acute Pulmonary Embolism of the European Society of Cardiology (ESC). Eur Heart J. 2008;29:2276-2315.

42. Jimenez D, Aujesky D, Moores L, Gomez V, Lobo JL, Uresandi F, et al. Simplification of the pulmonary embolism severity index for prognostication in patients with acute symptomatic pulmonary embolism. Arch Intern Med. 2010;170:1383-1389.

43. Aujesky D, Obrosky DS, Stone RA, Auble TE, Perrier A, Cornuz J, et al. Fine MJ. A prediction rule to identify low-risk patients with pulmonary embolism. Arch Intern Med. 2006;166:169-75.

44. Lobo JL, Zorrilla V, Aizpuru F, Grau E, Jiménez D, Palareti G, et al. RIETE Investigators. D-dimer levels and 15-day outcome in acute pulmonary embolism. Findings from the RIETE Registry. J Thromb Haemost. 2009;7(11):1795-801.

45. Fremont B, Pacouret G, Jacobi D, Puglisi R, Charbonnier B, de Labriolle A. Prognostic value of echocardiographic right/left ventricular end-diastolic diameter ratio in patients with acute pulmonary embolism: results from a monocenter registry of 1,416 patients. Chest 2008;133(2):358-362.

46. Sanchez O, Trinquart L, Colombet I, Durieux P, Huisman MV, Chatellier G, et al. Prognostic value of right ventricular dysfunction in patients with haemodynamically stable pulmonary embolism: a systematic review. Eur Heart J. 2008;29(12):1569-1577.

47. Lega JC, Lacasse Y, Lakhal L, Provencher S. Natriuretic peptides and troponins in pulmonary embolism: a meta-analysis. Thorax. 2009;64(10):869-75.

48. Becattini C, Vedovati MC, Agnelli G. Prognostic value of troponins in acute pulmonary embolism: a meta-analysis. Circulation. 2007;116(4):427-433.

49. Konstantinides S. Clinical practice. Acute pulmonary embolism. N Engl J Med. 2008;359:2804-2813.
50. Raschke RA, Gollihare B, Peirce JC. The effectiveness of implementing the weight-based hepatic nomogram as a practice guideline. Arch Intern Med. 1996;156:1645-49.

51. Levine MN, Hirsh J, Gent M, Turpie AG, Cruickshank M,Weitz J et al. A randomized trial comparing activated thromboplastin time with heparin assay in patients with acute venous thromboembolism requiring large daily doses of heparin. Arch Intern Med. 1994;154:49-56.

52. Quinlan DJ, McQuillan A, Eikelboom JW. Low-molecular-weight heparin compared with intravenous unfractionated heparin for treatment of pulmonary embolism: a meta-analysis of randomized, controlled trials. Ann Intern Med. 2004;140:175-83.

53. Erkens PM, Prins MH. Fixed dose subcutaneous low molecular weight heparins versus adjusted dose unfractionated heparin for venous thromboembolism. Cochrane Database Syst Rev. 2010;8(9):CD001100

54. Samama MM, Poller L. Contemporary laboratory monitoring of low molecular weight heparins. Clin Lab Med. 1995;15:119-123.

55. Bounameaux $\mathrm{H}$, de Moerloose $\mathrm{P}$. Is laboratory monitoring oflow-molecular-weight heparin therapy necessary? No. J Thromb Haemost 2004; 2: 551-54.

56. Antman, EM, Anbe, DT, Armstrong, PW, et al. ACC/AHA Guidelines for the Manage

ment of Patients With ST-Elevation Myocardial Infarction-Executive Summary: A Report of the American College of Cardiology/American Heart Association Task Force on Practice Guidelines (Writing Committee to Revise the 1999 Guidelines for the Management of Patients With Acute Myocardial Infarction). Circulation 2004;110:588-636.)

57. Vedantham S, Grassi CJ, Ferral H, Patel NH, Thorpe PE, Antonacci VP, et al. Technology Assessment Committee of the Society of Interventional Radiology. Reporting standards for endovascular treatment of lower extremity deep vein thrombosis. J Vasc Interv Radiol 2006;17:417-434.

58. Sukhija R, Aronow WS, Lee J, Kakar P, McClung JA, Levy JA, et al. Association of right ventricular dysfunction with in-hospital mortality embolectomy. Am J Cardiol. 2005;95:695- 696 


\section{REVIEW ARTICLE}

59. Skaf E, Beemath A, Siddiqui T, Janjua M, Patel NR, Stein PD. Catheter-tip embolectomy in the management of acute massive pulmonary embolism. Am J Cardiol. 2007;99:415-420.

60. Meneveau N, Seronde MF, Blonde MC, Legalery P, Didier-Petit K, Briand F, et al. Management of unsuccessful thrombolysis in acute massive pulmonary embolism. Chest 2006;129:1043-1050.
61. IorioA, Guercini F, Pini M. Low-molecular weight heparin for the long-term treatment of symptomatic venous thromboembolism: mea-analysis of the randomized comparisons with oral anticoagulants. J Thromb Haemostat 2003;1:1906-13

62. Van der Heijden JF, Hutten BA, Büller HR, Prins $\mathrm{MH}$. Vitamin K antagonists or low-molecular weight heparin for the long term treatment of symptomatic venous thromboembolism. Cochrane Database System Rev 2002(1):CD002001. 